\title{
European guidelines for quality assurance in colorectal cancer screening and diagnosis. First Edition Quality assurance in pathology in colorectal cancer screening and diagnosis

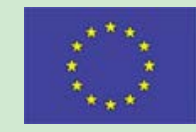 \\ Co-Funded by the Health Programme of the European Union
}

Authors

Institutions
P. Quirke' ${ }^{1}$ M. Risio ${ }^{2}$, R. Lambert ${ }^{3}$, L. von Karsa ${ }^{4}$, M. Vieth ${ }^{5}$

Institutions are listed at the end of article.
Keywords

mass screening

colorectal neoplasms

- histopathology

- classification

- precursor lesions

- multidisciplinary evidencebased guidelines

population-based programmes

\section{Bibliography}

Dol http://dx.doi.org/ 10.1055/s-0032-1309797 Endoscopy 2012; 44: SE116-SE130 (c) Georg Thieme Verlag KG Stuttgart · New York ISSN 0013-726X

\section{Corresponding author \\ P. Quirke}

Pathology and Tumour Biology Leeds Institute of Molecular Medicine

St. James's University Hospital University of Leeds Leeds

United Kingdom p.quirke@leeds.ac.uk qas@iarc.fr
Multidisciplinary, evidence-based guidelines for quality assurance in colorectal cancer screening and diagnosis have been developed by experts in a project coordinated by the International Agency for Research on Cancer. The full guideline document covers the entire process of populationbased screening. It consists of 10 chapters and over 250 recommendations, graded according to the strength of the recommendation and the supporting evidence. The 450-page guidelines and the extensive evidence base have been published by the European Commission. The chapter on quality assurance in pathology in colorectal can-

\section{Background}

According to the most recent estimates by the International Agency for Research on Cancer [18] colorectal cancer (CRC) is the most common cancer in Europe with 432000 new cases in men and women reported annually. It is the second most common cause of cancer deaths in Europe with 212000 deaths reported in 2008. Worldwide CRC ranks third in incidence and fourth in mortality with an estimated 1.2 million cases and 0.6 million deaths annually. The European Union (EU) recommends population-based screening for breast, cervical and colorectal cancer using evidence-based tests with quality assurance of the entire screening process including diagnosis and management of patients with screen-detected lesions [9]. The EU policy takes into account the principles of cancer screening developed by the World Health Organization [85] and the extensive experience in the EU in piloting and implementing population-based cancer screening programmes [75]. Screening is an important tool in cancer control in countries with a significant burden of CRC, provided the screening services are high quality [76]. The presently reported multidisciplinary, evidence-based guidelines for quality assurance in colorectal cancer screening and cer screening and diagnosis includes 23 graded recommendations. The content of the chapter is presented here to promote international discussion and collaboration by making the principles and standards recommended in the new EU Guidelines known to a wider professional and scientific community. Following these recommendations has the potential to enhance the control of colorectal cancer through improvement in the quality and effectiveness of the screening process, including multi-disciplinary diagnosis and management of the disease.

diagnosis have been developed by experts and published by the EU [55].

\section{Methods}

$\nabla$

The methods used are described in detail elsewhere in this supplement [34]. Briefly, a multidisciplinary group of authors and editors experienced in programme implementation and quality assurance in colorectal cancer screening and in guideline development collaborated with a literature group consisting of epidemiologists with special expertise in the field of CRC and in performing systematic literature reviews. The literature group systematically retrieved, evaluated and synthesized relevant publications according to defined clinical questions (modified PatientIntervention-Comparison-Outcome-Study method). Bibliographic searches for most clinical questions were limited to the years 2000 to 2008 and were performed on Medline, and in many cases also on Embase and The Cochrane Library. Additional searches were conducted without date restrictions or starting before 2000 if the authors or editors who were experts in the field knew that there were relevant articles published before 2000. Articles of adequate quality recommended 
by authors because of their clinical relevance were also included. Only scientific publications in English, Italian, French and Spanish were included. Priority was given to recently published, systematic reviews or clinical guidelines. If systematic reviews of high methodological quality were retrieved, the search for primary studies was limited to those published after the last search date of the most recently published systematic review, i.e. if the systematic review had searched primary studies until February 2006, primary studies published after February 2006 were sought. If no systematic reviews were found, a search for primary studies published since 2000 was performed.

In selected cases references not identified by the above process were included in the evidence base, i.e. when authors of the chapters found relevant articles published after 2008 during the period when chapter manuscripts were drafted and revised prior to publication. The criteria for relevance were: articles concerning new and emerging technologies where the research grows rapidly, high-quality and updated systematic reviews, and large trials giving high contribution to the robustness of the results or allowing upgrading of the level of evidence.

The methodological quality of the retrieved publications was assessed using the criteria obtained from published and validated check lists. Evidence tables were prepared for the selected studies. The evidence tables, clinical questions and bibliographic literature searches are documented elsewhere [33].

In the full guidelines document prepared by the authors and editors [55] over 250 recommendations were formulated according to the level of the evidence and the strength of the recommendation using the following grading scales.

\section{Level of evidence:}

I multiple randomised controlled trials (RCTs)

of reasonable sample size, or systematic reviews (SRs) of RCTs

II one RCT of reasonable sample size, or 3 or less RCTs with small sample size

III prospective or retrospective cohort studies or SRs of cohort studies; diagnostic cross sectional accuracy studies

IV retrospective case-control studies or SRs of case-control studies, time-series analyses

V case series; before/after studies without control group, cross sectional surveys

VI expert opinion

\section{Strength of recommendation:}

A intervention strongly recommended for all patients or targeted individuals

B intervention recommended

C intervention to be considered but with uncertainty about its impact

D intervention not recommended

E intervention strongly not recommended

Some statements of advisory character considered to be good practice but not sufficiently important to warrant formal grading were included in the text.

\section{Results}

$\nabla$

Twenty-three graded recommendations are provided in Chapter 7.

\section{Recommendations $^{1}$}

\section{$\nabla$}

7.1 Due to the improved diagnostic reproducibility of the revised Vienna classification, use of this classification in a format modified for lesions detected in screening is recommended to ensure consistent international communication and comparison of histopathology of biopsies and resection specimens (IV-B). Only two grades of colorectal neoplasia (low grade and high grade) should be used, to minimise intraobserver and interobserver error (V-B). The terms intra-mucosal adenocarcinoma or in-situ carci-

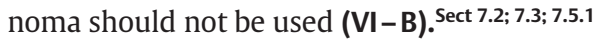

7.2 The WHO definition of colorectal adenocarcinoma should be used: "an invasion of neoplastic cells through the muscularis mucosae into the submucosa" (VI-A)..$^{\text {ect }}$ 7.5.1

7.3 Adenocarcinomas should be reported according to the TNM classification. The version of TNM to be used should be decided nationally and should be stated e.g. pT1 pN0 pMX (Version 5) or pT4 pN2 pM1 (Version 7). These can be further abbreviated to pT1N0MX (v5) or to PT4N2M1 (v7) (VI-B). . $^{\text {Sect 7.6.5.1 }}$

7.4 The WHO classification of adenomas into tubular, tubulovillous and villous should be used ( $\mathrm{VI}-\mathrm{A})$. .ect $7.2^{2}$

7.5 Due to the increased risk of colorectal cancer associated with flat and/or depressed lesions they should be reported as non-polypoid lesions (III), and further classified by the

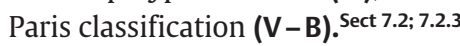

7.6 The pathologist should verify the complete removal of neoplastic lesions (clear margins) and the absence of submucosal invasion in biopsy specimens. Currently we recommend that clearance of $1 \mathrm{~mm}$ or less indicates margin involvement (VI-B). Cases of incomplete removal or uncertainty about submucosal invasion should be highlighted in the pathology report (VI-B). .ect $7.6 .3^{\text {7.6. }}$

7.7 Sub-staging of T1 cancers should be performed to determine the risk of residual disease. Consideration should be given to the appropriate method, which may vary depending on the morphology of the lesion (Kikuchi/Haggitt or measurement). For non-polypoid lesions the Kikuchi stage and for pedunculated lesions Haggitt are currently recommended (VI-C). High-risk features for residual disease such as lack of margin clearance $(\leq 1 \mathrm{~mm})$, poor differentiation and lymphatic and vascular invasion should be reported ( $\mathbf{V}-\mathbf{B})$. The multidisciplinary team should be consulted on whether or not surgical resection of pT1 adenocarcinoma is recommended; if surgical resection is recommended, consideration should be given to obtaining an opinion from a second histopathologist as variation exists in evaluating high-risk features ( $\mathrm{VI}-\mathrm{A})$. $^{\text {Sect } 7.5 .3}$

7.8 The size of lesions should be carefully measured by the pathologist to the nearest $\mathrm{mm}$ on the haematoxylin and eosin slide, or on the fixed specimen when the largest dimension of the lesion cannot be reliably measured on the slide. Endoscopy measurements are less accurate and

\footnotetext{
1 Sect (superscript) after each recommendation in the list refers the reader to the section/s of the Guidelines dealing with the respective recommendation*.

$\operatorname{Rec}$ (superscript) throughout the chapter refers to the number of the recommendation dealt with in the preceding text*.

${ }^{*}$ The first digit of the section numbers and recommendation numbers refers to the respective chapter in the guidelines. For Chapters 1 to 6 see: [29, $31,35,21,70,63]$ and for Chapters 8 to 10 see: [62,1,2] respectively.
} 
should only be used when strictly necessary, e.g. if the lesion is fragmented (III-B). Given the small dimensions of the submucosal layer, infiltration into the submucosal level should be measured in microns from the bottom line

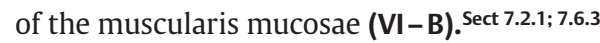

7.9 Programmes should have a policy on the methodology of, and should regularly monitor the accuracy of size measurements of endoscopically removed lesions. Deviation between the actual size and the measurements of pathologists and endoscopists should be minimised. Management decisions which depend on lesion size should take into account potential inaccuracy in the size measurement. The multidisciplinary team should consider deviating from the recommended size categories in treatment and surveillance algorithms, if the review of a case indicates that there is sufficient reason to doubt the accuracy of the measurement. Such cases should be captured as an auditable outcome (VI-B). ${ }^{\text {Sect 7.2.1 }}$

7.10 Hyperplastic polyps are non-neoplastic and their complete removal is optional. All other lesions in the serrated pathway should be excised and serrated lesions with neoplasia should be followed up (surveillance) as if they were adenomas (VI- C). Sect 7.1; 7.2.4.4-5

7.11 All biopsies and lesions identified in the screening programme and the subsequent resection specimen should be reported on a proforma (IV-B) in a timely manner and in a minimum of $90 \%$ of all cases. The proforma should be sent to the referring physician, the relevant cancer registry and the screening programme (VI-B). .ect 7.6.5.2; 7.8 $^{\text {s. }}$

7.12 Dissection of all specimens should be according to national guidelines. If national guidelines do not exist they should be created or adopted from elsewhere. An additional free text written report is optional, but must include all of the data required in the proforma $(\mathbf{V I}-\mathbf{B}) .^{\text {sect 7.6.5.2 }}$

7.13 The correlation between histological diagnosis of biopsy and surgical specimens should be reported. Any lack of correlation should be discussed by the multi-disciplinary team, and the results of this discussion should be documented (III-B). Sect $7.8^{-1}$

7.14 Pathologists must ensure that their proformas are received by the screening programme coordinators or a cancer registry for the purposes of clinical management, audit and quality assurance. Results from the key indicators of quality should be returned to the funding body: either the Health Authority or the national screening programmes' offices for analysis (VI-B). . $^{\text {Sect } 7.8}$

7.15 Statistics should include the frequency of colorectal cancer and the distribution of TNM stages and version used, as well as the distribution of the type of lesion, size, location, frequency of grades of neoplasia and villousness (villous, tubulo-villous or tubular) and presence of non-neoplastic lesions (VI-B). Sect 7.8; 7.5.3.6

7.16 There should be good communication between the members of the screening team with agreed terminology, regular meetings and clinical discussions (VI-B). .ect $7.7^{\text {. }}$

7.17 Pathologists taking part in a colorectal cancer screening programme must participate regularly in multi-disciplinary team meetings, and twice a year in an external quality assurance programme that has external oversight of the

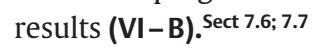

7.18 Departments and individual pathologists should audit their own reporting practices for key features (VI-B)..$^{\text {Sect }} 7.7$
7.19 Pathologists reporting in a colorectal cancer screening programme must meet their national criteria for safety in reporting colorectal cancer ( $\mathbf{V I}-\mathbf{B}) .^{\text {Sect }} 7.7$

7.20 Departments and pathologists taking part in screening programmes should audit the number of lymph nodes retrieved, the frequency of circumferential resection margin involvement and the frequency of high-risk features such as extramural vascular invasion, tumour perforation and peritoneal invasion reported ( $\mathbf{V I}-\mathbf{B}) .^{\text {Sect }} \mathbf{7 . 7}$

7.21 Pathologists reporting in a colonoscopy screening programme should not report high-grade neoplasia in more than $5 \%$ of lesions and those in an FOBT programme in not more than $10 \%$ of lesions (VI-B). .ect $^{7.7}$

7.22 Pathologists should attend one refresher training course every year on the pathology of colorectal neoplasia to maintain quality (VI-B). sect $7.6^{-6}$

7.23 Laboratories participating in a screening programme must be able to demonstrate participation in a laboratory technical external quality assurance programme and hold external accreditation for their services (VI-C). ${ }^{\text {Sect }} 7.7$

Further detailed information can be found in the annex to this chapter [73].

\subsection{Introduction}

The pathology service plays a very important role in colorectal cancer screening since the management of participants in the programme depends on the quality and accuracy of the diagnosis. Pathology affects the decision to undergo further local and/ or a major resection as well as surveillance after screening. The adoption of formal screening programmes leads to improvement not only in the management of early but also advanced disease by the introduction of guidelines, quality standards, external quality assurance and audit. In screening programmes, the performance of individuals and programmes must be assessed and it is advantageous if common diagnostic standards are developed to ensure quality, recognise areas where sufficient evidence is still lacking, and initiate high-quality studies to answer these questions. The present chapter suggests practical guidelines for pathology within a colorectal screening programme. We have concentrated on the areas of clinical importance in the hope of standardising these across the European Union. In the associated annex [73] we deal with some of the more difficult areas and suggest topics for future research. We have included guidelines for the reporting and management of resected specimens in an attempt to move towards agreed minimum European standards of pathology in these areas as well. This is the first edition of what will be a continuing process of revision as new data emerge on the pathology, screening and management of colorectal cancer. We hope to set minimum standards that will be followed in all programmes and to encourage the development of higher standards amongst the pathology community and screening programmes.

Many lesions are found within a screening programme some of which are of little or no relevance to the aim of lowering the burden of colorectal cancer in the population. The range of pathology differs between the different approaches, with faecal occult blood programmes yielding later, more advanced disease than flexible sigmoidoscopy and colonoscopy screening. Programme activities must focus on the identification and appropriate management of invasive colorectal cancer and its precursors. The management of pre-invasive lesions involves surveillance to allow the prevention of future disease, whereas management of adenocarcinoma focuses on immediate treatment and decisions 
Table 7.1 Adaptation of the revised Vienna classification ${ }^{1}$ for colorectal cancer screening.

\section{NO NEOPLASIA: ${ }^{2}$ \\ Vienna Category 1 (Negative for neoplasia) \\ 2. MUSCOSAL LOW GRADE NEOPLASIA: \\ Vienna category 3 (Mucosal low-grade neoplasia \\ Low-grade adenoma \\ Low-grade dysplasia); \\ Other common terminology \\ mild and moderate dysplasia; \\ WHO: low-grade intra-epithelial neoplasia}

\section{MUCOSAL HIGH GRADE NEOPLASIA:}

Vienna: Category 4.1 - 4.4 (Mucosal high grade neoplasia

high-grade adenoma/dysplasia

Non-invasive carcinoma (carcinoma in situ)

Suspicious for invasive carcinoma

Intramucosal carcinoma);

Other common terminology

severe dysplasia

high-grade intraepithelial neoplasia;

WHO: high-grade intraepithelial neoplasia

TNM: $\mathrm{PT}$ is

4. CARCINOMA invading the submucosa or beyond:

4a. Carcinoma confined to submucsa

Vienna: Category 5 (Submucosal invasion by carcinoma);

TNM: PT1

4b. Carcinoma beyond submucosa

TNM: PT2-T4

${ }^{1}$ For revised Vienna classification see [14], for WHO classification see [81], for TNM see [58-60].

${ }^{2}$ Category 2 of the Vienna Classification (indefinite) is not recommended for screening.

on local removal, or radical surgery with the potential for operative mortality. Overuse of radical surgery must be avoided and recommendations for its use must be balanced with the risks to the patient.

There are a number of lesions, especially in the serrated pathway leading from hyperplastic polyps to other serrated lesions and in some cases to adenocarcinoma, that may be difficult to diagnose and for which knowledge of their natural history and clinical implications is limited [57]. Further work is required in this area, but until we understand these lesions better it is recommended that all serrated lesions, with the exception of hyperplastic polyps, be fully removed ( $\mathbf{V}-\mathbf{B}) .^{\operatorname{Rec} 7.10}$

Few data were present in the literature on this issue. This paucity of data is caused in part by a lack of standardisation in terminology and limited observer agreement. Furthermore, a lack of prospective studies precludes a clear indication of the optimal treatment and surveillance strategy for lesions in the serrated pathway. For more information, see the annex to this chapter [73]. The screening programme will also identify other non-serrated neoplastic and non-neoplastic lesions and provide important data on such conditions.

\subsection{Classification of lesions in the adenoma-carcinoma sequence}

A colorectal adenoma is defined as a lesion in the colon or rectum containing unequivocal epithelial neoplasia. Classification of adenomas should include grading of neoplasia according to the revised Vienna classification that has been modified for the Euro- pean Guidelines to obtain a two-tiered system of low-grade and high-grade neoplasia ( $\bullet$ Table 7.1); see also Kudo et al. [28]. This modified grading system aims to minimise intra- and inter-observer variation and facilitate management of endoscopically detected lesions by improving correlation between histopathology of biopsies and resection specimens [67]. Classically, adenomas are divided into tubular, tubulo-villous or villous types and demarcation between the three is based on the relative proportions of tubular and villous components, according to the " $20 \%$ rule" described in the WHO classification of tumours in the digestive tract [81]. At least $20 \%$ of the estimated volume of an adenoma should be villous to be classified as a tubulo-villous adenoma and $80 \%$ villous to be defined as a villous adenoma. All other lesions are classified as tubular [81] (VI-A). ${ }^{\text {Rec } 7.4}$ The reproducibility of villousness increases when collapsing the categories into only two: tubular vs. any villous component (i.e. anything $>20 \%$ villous). Adenomas can be endoscopically polypoid, flat or depressed. Due to the increased risk of colorectal cancer associated with flat and/or depressed lesions (III) they should be reported as non-polypoid lesions (see Sect. 7.2.3). The Paris endoscopic classification of superficial neoplastic lesions should be used to describe the gross appearance of colorectal adenomas (V-B). ${ }^{\text {Rec }} 7.5$ Key features to report in a programme are size, villousness, the grading of neoplasia, the recognition of invasion and features suggesting the need for further intervention either local or radical. The size of adenomas is important for their risk of containing an adenocarcinoma but it is also related to the need for subsequent surveillance, or colonoscopy.

The two-tiered grading of mucosal colorectal neoplasia recommended in the European Guidelines (see $\bullet$ Table 7.1) is based on the revised Vienna Classification that has improved diagnostic reproducibility, particularly for non-polypoid lesions [14,51,52, 64,65] (IV-B). ${ }^{\text {Rec }}{ }^{7.1}$ The recommended two-tiered grading system also permits translation of histopathology findings of Western and Japanese pathologists into a uniform system for classification of colorectal neoplastic lesions.

In screening programmes the use of the term advanced adenoma has developed and is sometimes used to categorise adenomas for management. In this context an advanced adenoma is one that is either $\geq 10 \mathrm{~mm}$ or contains high-grade mucosal neoplasia or a villous component.

The hyperplastic polyp must be distinguished from other serrated lesions due to its extremely low malignant potential. The significance of other lesions in the serrated spectrum is controversial and our knowledge is still developing; traditional serrated adenomas and mixed polyps with neoplasia should be considered as adenomas for the purpose of follow-up (surveillance). More details are provided in the annex [73].

\subsubsection{Measurement of size of adenomas}

Size (largest diameter) is an important objective measurement best performed by the pathologist [54] from the slide, as is recommended in the EU Guidelines for breast cancer screening [15]. Endoscopy measurements are less accurate and should only be used when strictly necessary (III-B). ${ }^{\text {Rec }} 7.8$ Pathology measurements are auditable, accurate, simple to perform and able to assess the size of the adenomatous component of mixed lesions. Although the quality of evidence is low, there are some indications that different modalities of advanced adenoma measurement (endoscopic measurement vs. pathologist's measurement before and after fixation, slide preparation) can affect diagnostic reproducibility and the detection rate of advanced adeno- 
mas. An overestimation or underestimation of a large or a small polyp is important when the misjudgement crosses the $10 \mathrm{~mm}$ threshold. It seems that the use of the pathologist's measurement is currently the most accurate. If the lesion is too large for the maximum dimension to be measured by this method, because it cannot be represented on a single slide, the measurements taken at the time of specimen dissection should be used. If a biopsy is received or the specimen is fragmented it should be stated that it cannot be accurately assessed for size by the pathologist and the endoscopy measurements should be used. Measurements should exclude the stalk if it is composed of normal mucosa however the distance to the excision margin should be noted. The size of adenomas is used to determine the need for surveillance and therefore must be measured accurately to the nearest millimetre (and not rounded-up to the nearest 5 or $10 \mathrm{~mm}$ ). Where the lesion is mixed or only part of a lesion is adenomatous, measurement should be performed on the adenomatous component.

Programmes should have a policy on the methodology of, and should regularly monitor the accuracy of size measurements of endoscopically removed lesions. Deviation between the actual size and the measurements of pathologists and endoscopists should be minimised. Management decisions that depend on lesion size should take into account potential inaccuracy in the size measurement. The multidisciplinary team should consider deviating from the recommended size categories in treatment and surveillance algorithms, if the review of a case indicates that there is sufficient reason to doubt the accuracy of the measurement. Such cases should be captured as an auditable outcome (VI-B). ${ }^{\text {Rec }} 7.9$

\subsubsection{Tubular, tubulo-villous and villous adenomas: the typing of villousness}

The $20 \%$ rule only applies to wholly excised polyps and to intact sections of lesions large enough to provide reliable proportions. For small fragmented lesions or superficial polyp biopsies, the presence of at least one clearly identifiable villus merits classification as "at least tubulo-villous". Definitions of the types of villousness are presented in the annex [73].

\subsubsection{Non-polypoid adenomas}

The role of the pathologist in the evaluation of non-polypoid adenomas is to confirm the adenomatous nature of the lesion, and to determine the grade of neoplasia as well as the depth of depression in the case of a depressed non-polypoid lesion (see below). Since the expression "flat adenoma" is not well defined it is recommended to group together all adenomatous lesions other than polypoid into the category of "non-polypoid adenomas" and avoid the term "flat". Non-polypoid adenomas correspond to an endoscopical diagnosis of neoplasia in the subtypes IIa, IIb and IIc according to the Paris classification. Completely flat adenomas (type IIb) and depressed lesions (type IIc) are rarely found in the colon and rectum, while slightly elevated lesions (type IIa) are frequent. In the literature, the height of non-polypoid adenomas has been described histologically as not exceeding twice the height of normal mucosa, thus measuring less than $3 \mathrm{~mm}$ in height. This definition may be difficult to apply due to fixation artefacts and in slightly depressed lesions since the adjacent mucosa may be thinner than the normal epithelium. The endoscopic diagnosis of a non-polypoid lesion should be reported according to the Paris classification $[28,61,65,66]$ (III-B). ${ }^{\text {Rec }} 7.5$ We were unable to retrieve studies that specifically address the topic of the differences in the detection rates of non-polypoid colorectal neo- plasms among the different types of screening programmes (FOBT vs. FS vs. TC), although a prevalence of $9-10 \%$ of non-polypoid colorectal neoplasm (flat and depressed) was recently reported by Western pathologists in a large cross-sectional study [61]. Depressed lesions (type IIc) should be mentioned in the histological report for clinico-pathological correlation. Special care should be taken for centrally depressed lesions, especially when the depression is deeper than half of the adjacent lesion. These are reported to have a higher frequency of high-grade neoplasia and invasion at a smaller size than other flat or depressed lesions [28]. Non-polypoid adenomas can show so-called lateral spread with poor delineation of the margins thus making endoscopic removal difficult.

\subsubsection{Serrated lesions}

\subsubsection{Terminology}

These lesions have in common a serrated morphology, but depending on other characteristics, the potential to develop into invasive adenocarcinoma differs considerably. Serrated lesions vary from the hyperplastic polyp, which although relatively common, has no implications for the screening programme unless very numerous, proximally located or of a large size $(>10 \mathrm{~mm})$, to sessile serrated lesions (sometimes referred to as sessile serrated polyps/sessile serrated adenomas), traditional serrated adenomas, or mixed lesions/mixed polyps. Serrated lesions are infrequent, the evidence base is poor and recommendations are not well established, but until further evidence is forthcoming we recommend the following:

\subsubsection{Hyperplastic (metaplastic) polyp}

Hyperplastic polyps (HPs) are often small lesions $(<5 \mathrm{~mm}$ in diameter), frequently found in the left (distal) colon. They are composed of simple elongated crypts with a serrated structure in the upper half. These polyps usually show some proliferation in the basal (non-serrated) part of the crypts (regular proliferation). Nuclei are small, regular and basally orientated. There is no hyperchromasia, and stratification of the upper half of the crypts has a serrated appearance without cytological atypia.

Hyperplastic polyposis should be excluded in cases with giant hyperplastic polyps ( $>10 \mathrm{~mm}$ ), or multiple hyperplastic polyps in the right colon, or in first-degree relatives of individuals with hyperplastic polyposis.

\subsubsection{Sessile serrated lesions}

We recommend the use of the term sessile serrated lesion (SSL) for serrated lesions with structural alterations that do not show mucosal neoplasia. This term should replace the use of sessile serrated polyp and sessile serrated adenomas until better definitions are created. ${ }^{2}$ It is not recommended to use the latter terms in screening programmes because it would add additional ill-defined categories that may confuse practitioners.

\footnotetext{
2 The term sessile serrated polyp has been proposed elsewhere for serrated lesions that cannot be definitely classified into the category of hyperplastic polyps or serrated adenomas [57], especially in cases with technical inconsistencies such as tangential cuts or superficial biopsies. The same terminology has been proposed for lesions with minimal and focal structural alterations in the absence of cytological atypia [68].
} 


\subsubsection{Traditional serrated adenomas}

If the lesion shows a serrated morphology as well as mucosal neoplasia (cytological abnormalities), it is considered to be a traditional serrated adenoma (TSA) [30]. It should be reported as such (TSA) and treatment and surveillance should be the same as for adenomas. See annex [73] and Chapter 9 [1] for details. This pragmatic recommendation recognises the neoplastic nature of these lesions. The non-serrated features found in such lesions (e.g. size and grade of neoplasia) and any co-existing pathology (e.g. number of neoplastic lesions) should be taken into account in selecting an appropriate surveillance protocol (VI-C). Rec 7.10

\subsubsection{Mixed polyp}

These are lesions with combinations of more than one histopathologic type in the serrated spectrum (hyperplastic polyps, sessile serrated lesions, traditional serrated adenomas) or at least one type in combination with adenoma [23]. The important feature to recognise for the screening programme is the presence of neoplasia. The respective types of lesion in a mixed polyp should be reported and the term "mixed polyp" should only be used in brackets after the diagnosis of the individual components (e.g. adenoma and hyperplastic polyp, or traditional serrated adenoma plus adenoma). Mixed polyps should be completely removed. If there is an adenomatous component, the lesion should be followed up (surveillance) in the same manner as for adenomas, taking into account the size and the grade of the adenomatous component. (VI-C). ${ }^{\operatorname{Rec}} 7.10$

\subsection{Grading of neoplasia}

The revised Vienna classification has been adopted here, but in a simplified form suitable for screening and diagnosis, by removing the indefinite category between "negative for neoplasia" and "low-grade neoplasia". This category has no clinical value and unlike inflammatory bowel disease is likely to be chosen very infrequently. Excluding it reduces the number of categories and simplifies the subsequent management choices. The advantages of the revised Vienna Classification on which the European screening classification is based are that it improves diagnostic reproducibility $[14,52,64,65]$ (IV-B). The modified format with a two-tiered grading of mucosal colorectal neoplasia aims to further reduce inter-observer variation [17] (V-B). ${ }^{\text {Rec }} 7.1$ It encompasses the diagnostic categories used in the Eastern and the Western schools and each level has a clinical consequence. In the revised Vienna classification the term neoplasia is used which is synonymous with the formerly used term "dysplasia". In the twotiered grading system recommended in the European Guidelines, mucosal low-grade neoplasia corresponds to neoplasia of the same grade in the revised Vienna classification; mucosal highgrade neoplasia likewise corresponds to neoplasia of the same grade in the revised Vienna classification. Invasive submucosal neoplasia in the European classification corresponds to carcinoma invading the submucosa or beyond in the Vienna classification (see $\bullet$ Table 7.1).

\subsubsection{Low-grade neoplasia}

Low-grade neoplasia is an unequivocal neoplastic condition confined to the epithelial glands. It should not be mistaken for inflammatory or regenerative changes. Alterations characteristic for low-grade neoplasia start from one gland and develop into a microadenoma that then grows to become macroscopically visi- ble. Caution should be exercised in patients with chronic inflammatory bowel disease where the diagnosis of a neoplastic sporadic adenoma has implications different from that of neoplasia in colitic mucosa.

\subsubsection{High-grade neoplasia}

The changes of high-grade neoplasia should involve more than just one or two glands (except in tiny biopsies of polyps), and should therefore be identifiable at low-power examination. Caution should be exercised in over-interpreting isolated surface changes that may be due to trauma, erosion or prolapse.

High-grade neoplasia is diagnosed on structure, supplemented by an appropriate cytology. Hence its presence is nearly always suspected by the low-power appearances where complex structural abnormalities are present in structures whose epithelium looks thick, blue, disorganised and with focal cell debris and necrosis. $^{3}$ The structural features are:

- complex glandular crowding and irregularity (note that the word "complex" is important and excludes simple crowding of regular tubules that might result from crushing);

- prominent glandular budding;

- a cribriform appearance and "back to back" glands; and

- prominent intraluminal papillary tufting.

While many of these features often co-exist in high-grade neoplasia, individually they are neither necessary nor usually sufficient. Indeed they may occasionally occur in lower grades of neoplasia and that is why it is necessary to further scrutinise the cytological features for signs of high-grade neoplasia. The cytological features of high-grade neoplasia are:

- loss of cell polarity or nuclear stratification. High-grade neoplasia should show at least $2-5$ nuclear rows and preferably a variable number of rows within individual glands. The nuclei are haphazardly distributed within all three thirds of the height of the epithelium. No maturation of the epithelium is seen towards the luminal surface;

- neoplastic goblet cells (retronuclear/dystrophic goblet cells);

- cytology includes vesicular or/and irregular round nuclei with loss of polarity whereas spindle-like palisading nuclei are a sign of low-grade intraepithelial neoplasia;

- markedly enlarged nuclei, often with a dispersed chromatin pattern and a prominent nucleolus;

- atypical mitotic figures; and

prominent apoptosis, focal cell debris and necrosis.

Again, these features usually coexist in high-grade neoplasia, and caution must be exercised in using just one. It should be emphasised again that they should occur in a background of complex structural abnormality. Marked loss of polarity and nuclear stratification sometimes occurs on the surface of small, structurally regular, tubular adenomas that otherwise have a lower grade of neoplasia, probably as a result of trauma, and must not be used to classify a lesion as high grade. The only exception to the rule is when the specimen consists of just a small biopsy from a polyp, when there is insufficient tissue to assess the architecture properly. In this situation it is permissible to label florid cytological abnormalities alone as high-grade neoplasia, but this will usually lead to re-excision of the whole polyp, when it will be possible to assess the whole lesion properly.

\footnotetext{
${ }^{3}$ High-grade neoplasia also contains the subgroup of intramucosal carcinoma used by some pathologists but not recommended here. For details see the annex.
} 
Also included within high-grade neoplasia is the presence of definite invasion into the lamina propria of the mucosa but not invasion through the mucscularis mucosae.

\subsection{Other lesions}

\subsubsection{Inflammatory polyps}

Experience from United Kingdom pilot sites has shown that inflammatory-type polyps are relatively common. Whilst they are most usually seen as a complication of chronic inflammatory bowel disease, particularly ulcerative colitis, they are also seen in association with diverticulosis, mucosal prolapse and at the site of ureterosigmoidostomy. Furthermore, sporadic, single inflammatory-type polyps (inflammatory cap polyp, cloacogenic inflammatory polyp, myoglandular polyp, granulation tissue polyp etc.) are well described in the colorectum. As the reporting pathologist may not know the true context of such polyps, we recommend that all such polyps be classified as "post inflammatory polyp". The term inflammatory pseudopolyp (or even just "pseudopolyp") should be avoided. Biopsies with mucosal prolapse syndrome should be identified and reported as such and not as neoplastic conditions.

\subsubsection{Juvenile polyps}

Juvenile polyps are spherical in shape, show an excess of lamina propria, and have cystically dilated glands. The expanded lamina propria shows oedema and mixed inflammatory cells. Experience from the UK faecal occult blood pilot sites suggests that occasional juvenile-type polyps are identified, even in the screening age group [25]. Juvenile polyps are most common in children but occasional examples are seen in adults. We advise that any polyp showing juvenile polyp-type features should be classified as "juvenile polyp" for the purposes of diagnostic reporting in a screening programme. Juvenile polyps often show epithelial hyperplasia but neoplasia is very rare. Single sporadic juvenile polyps have a smooth surface, can be found in all age groups and often are eroded. So-called "atypical juvenile polyps" show different morphological features, with a multilobated architecture, intact surface mucosa and (usually) a much more pronounced epithelial component. They are a characteristic feature of juvenile polyposis (JP).

\subsubsection{Peutz-Jeghers polyps}

Whilst these polyps are usually seen in the Peutz-Jeghers syndrome, occasional examples are demonstrated as single, sporadic polyps in the colon. There remains uncertainty as to whether "inflammatory myoglandular polyp" represents a similar entity. As with juvenile polyposis, it would seem most unlikely, given the rarity of the syndrome and the age of the screening population, that Peutz-Jeghers syndrome would be diagnosed as part of a screening programme. Although Peutz-Jeghers polyps are classified as hamartomas, they have a very organised structure. They have a central core of smooth muscle with conspicuous branching, each branch being covered by colorectal-type mucosa that appears hyperplastic but not neoplastic. As with sporadic juvenile polyps, solitary Peutz-Jeghers-type polyps are most unlikely to demonstrate foci of neoplasia.

\subsubsection{Serrated (hyperplastic) polyposis}

This condition is characterised by one or more of the following conditions [6]:

- At least 5 histologically diagnosed serrated polyps proximal to the sigmoid colon, of which 2 are $>10 \mathrm{~mm}$;

- Any number of serrated polyps occurring proximal to the sigmoid colon in an individual who has a first-degree relative with hyperplastic polyposis; and/or

- More than 30 serrated polyps of any size, but distributed throughout the colon.

As mentioned in Section 7.2.4.2, hyperplastic polyposis should be excluded in cases with giant hyperplastic polyps (>10 mm), hyperplastic polyps in the right colon or in first-degree relatives of individuals with hyperplastic polyposis.

\subsubsection{Cronkhite-Canada syndrome}

We believe it is most unlikely that such cases will present via a screening programme and the true diagnosis may not be recognised by pathological assessment. However if Cronkhite-Canada syndrome is suspected, the pathologist should contact the endoscopist and ask for clinical details to ensure the diagnosis.

\subsubsection{Neuroendocrine tumour}

It is recommended to use the term "neuroendocrine tumour" rather than carcinoid in accordance with the WHO classification. These lesions are usually benign, small lesions and do not give rise to diagnostic difficulty.

\subsubsection{Colorectal intramucosal tumours with epithelial entrapment and surface serration}

Entrapment and pseudoinvasion of glands into the submucosal layer must be distinguished from invasive carcinoma. If in doubt, the relevant findings should be stated in the written report. If evaluation is problematic, step sections, a second opinion and further biopsies from the polypectomy ulcer should be considered.

\author{
7.4.8 Non epithelial polyps \\ - Lipoma \\ - Leiomyoma of the muscularis mucosae \\ - Ganglioneuroma \\ - Gastrointestinal schwannoma \\ - Neurofibroma \\ - GIST \\ - Various forms of vascular tumour \\ - Perineurioma \\ - Fibroblastic polyp \\ - Epithelioid nerve sheath tumour \\ - Inflammatory fibroid polyp
}

\subsection{Assessment of the degree of invasion of pT1 colorectal cancer}

pT1 cancers are those showing invasion through the muscularis mucosae into the submucosa but not into the muscularis propria.

\subsubsection{Definition of invasion}

We recommend the use of the WHO definition [80, 81] of an adenocarcinoma as an invasion of neoplastic cells through the muscularis mucosae into the submucosa (VI-A). ${ }^{\text {Rec }} 7.2$ The term intramucosal carcinoma should be substituted by mucosal high-grade neoplasia according to the WHO classification and the modified classification of neoplasia recommended in the European Guide- 
lines based on the revised Vienna classification (see $\bullet$ Table 7.1). We recognise that this will not allow detailed comparison with Japanese series where, contrary to the previous US and European literature, a diagnosis of carcinoma can be made on cases of neoplasia without submucosal invasion, or even on the basis of marked intraepithelial atypia. The TNM classification [58 - 60] allows carcinoma in situ (Tis) but this does not improve on the revised Vienna classification and should not be used. Please see annex for details [73] (VI-D). ${ }^{\text {eec }}$.1

Careful consideration should be given to the potential for surgical overtreatment of misclassified early T1 cancers. Screening programmes require explicit criteria for the diagnosis and staging of early adenocarcinoma because unnecessary radical resection will raise the morbidity and mortality in colorectal cancer screening programmes. Please see annex [73] for further discussion of this point. Post-operative mortality (within 30 days) ranges between $0.6 \%$ and $4.4 \%$ in $\mathrm{T} 1$ cancers depending on the population, age of patient and quality of services available. Achieving the optimum balance between removing all disease by resection and minimising harm is very important.

\subsubsection{Epithelial misplacement}

Epithelial misplacement of adenomatous epithelium into the submucosa of a polyp is a well-recognised phenomenon [36]. It is commonly seen in prolapsing polyps in the sigmoid colon. Experience suggests that this will be one of the most difficult areas of pathological diagnostic practice in FOBT screening. Sigmoid colonic polyps are particularly prone to inflammation, a feature that tends to enhance the neoplastic changes present. When associated with epithelial misplacement, the potential for misdiagnosis of these lesions as early carcinoma becomes much greater. In cases of epithelial misplacement, surrounding lamina propria and haemosiderin-laden macrophages are found. Submucosal mucinous lakes may be seen. These do not warrant an immediate diagnosis of invasion and must be interpreted in association with the surrounding features.

\subsubsection{High risk pT1 adenocarcinoma}

pT1 tumours provide many difficulties in a screening programme and the current evidence base for management of these lesions is poor and based on symptomatic patients $[4,7,10,22$, 74] (V-B). ${ }^{\text {Rec } 7.7}$ With regard to the correlation between clinical outcomes and tumour pathology, a clear indication of an increased risk of residual disease, lymph-node metastasis, haematogenous metastasis and mortality was observed after endoscopic polypectomy and subsequent surgical resection of poorly differentiated tumours (i.e. tumours with incomplete excision, poor grade of histological differentiation, venous and lymphatic invasion, tumour budding). Some pathology features, such as tumour budding and lymphatic and venous invasion appeared as possible prognostic factors for increased risk of lymph node me- tastasis but a clear guideline cannot be drawn as this correlation was not statistically significant in all studies. The available methods for sub-staging and differentiation grading are shown below. The most appropriate method depends on the morphology of the lesion and depth of invasion, e.g. non-polypoid-Kikuchi levels, and polypoid-Haggitt levels. In the future more quantitative measurements should be investigated as suggested by the Japanese.

\subsubsection{Sub-staging $\mathrm{pT} 1$}

In pT1 tumours the frequency of lymph node metastasis in tumours that involve the superficial, middle and deep thirds of the submucosa, i.e. so-called Kikuchi levels sm1, sm2 and sm3 (- Fig. 7.1) [26, 27] has been reported to be $2 \%, 8 \%$ and $23 \%$, respectively [37].

In pedunculated polypoid lesions, Haggitt identified the level of invasion into the stalk of the polyp ( $\bullet$ Fig. 7.2) as being important in predicting outcome and found that level 4 invasion, in which the tumour extended beyond the stalk of the polyp into the submucosa, but did not invade the muscularis propria, was an adverse factor [20].

However, both the Kikuchi (for non-polypoid tumours) and the Haggitt (for pedunculated tumours) systems may be difficult to use in practice, especially if there is fragmentation or suboptimal orientation of the tissue, and one study found lymph node metastases in 6 / 24 Haggitt level 3 lesions. More recently Ueno et al. [69] have proposed use of the depth $(>2000 \mu \mathrm{m})$ and width $(>4000$ $\mu \mathrm{m}$ ) of invasion measured in microns beyond the muscularis mucosae. This provides a more objective assessment of lymph node metastatic potential ( $2.5 \%$ vs. $18.2 \%$ when submucosal invasion width is < or $\geq 4000 \mu \mathrm{m}$, respectively; and $3.9 \%$ vs. $17.1 \%$, when submucosal invasion depth is <or $\geq 2000 \mu \mathrm{m}$, respectively; and this approach has been adopted in Japan. Each classification has advantages and disadvantages.

Kikuchi cannot be used in the absence of muscularis propria; Haggitt is not applicable in non-polypoid lesions, and measurement depends on a recognisable submucosa from which to measure. In view of the uncertainty and lack of consensus, a firm evidencebased recommendation for one method of assessing local invasion cannot yet be made. At present we recommend the Kikuchi stage for non-polypoid lesions and Haggitt for pedunculated lesions (VI-C). All three approaches must be evaluated in further large series from multiple programmes to derive adequately evidencebased recommendations.

\subsubsection{Tumour grade in $\mathrm{pT} 1$ lesions}

Poorly differentiated carcinomas are identified by the presence of either irregularly folded, distorted and often small tubules or the lack of any tubular formation and showing marked cytological pleomorphism. In the absence of good evidence we recommend that a grade of poor differentiation should be applied in a polyp

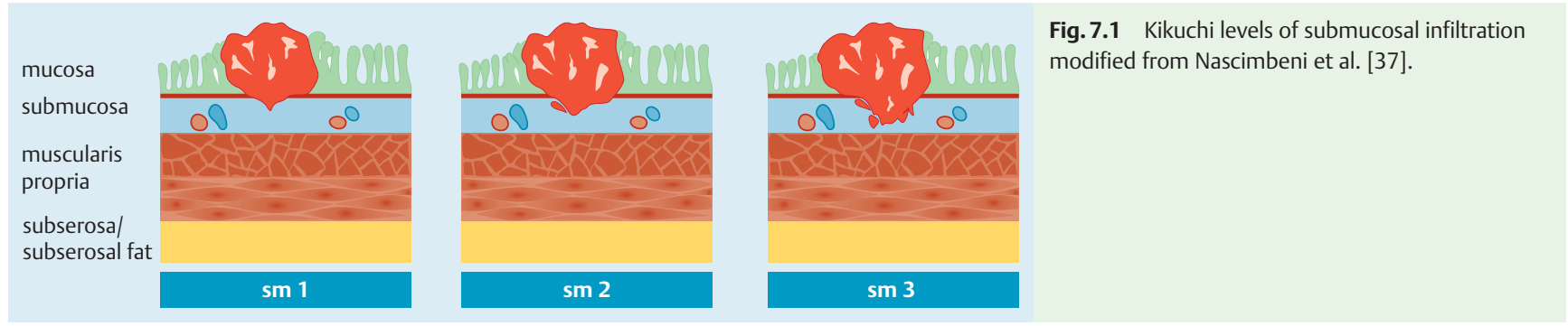




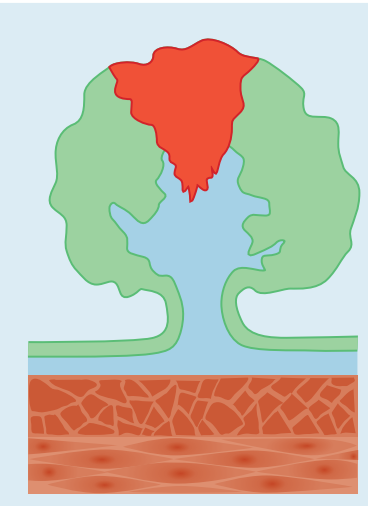

Level 1:

Invasion of the submucosa but limited to the head of the polyp.

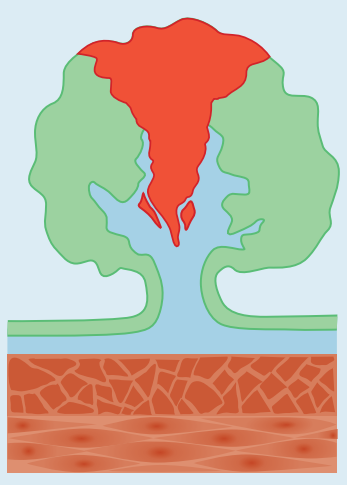

Level 2:

Invasion extending into the neck of polyp.

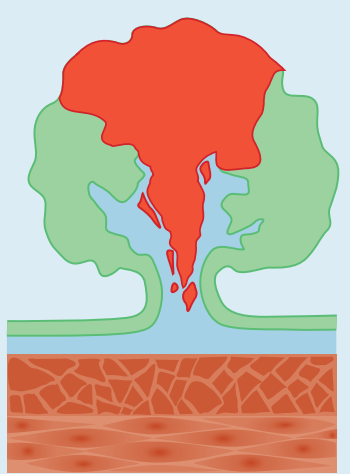

Level 3:

Invasion into any part ot the stalk.

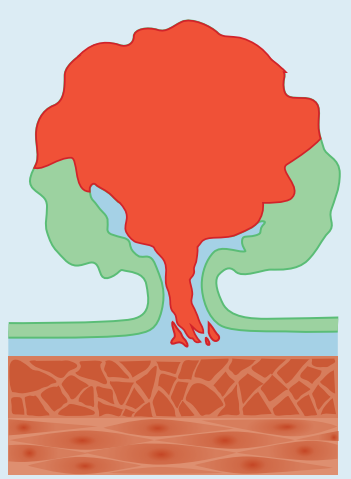

Level 4:

Invasion beyond the stalk but above the muscularis propria.

Fig. 7.2 Haggitt levels of invasion in polypoid carcinomas.

cancer when ANY area of the lesion is considered to show poor differentiation. Poor differentiation should equate to the WHO categories of poor and undifferentiated tumours [78]. The frequency should not exceed $20 \%$. According to the WHO classification [80], budding of the tumour cells at the front of invasion should not influence grading of the tumour. Please see annex for details [73].

\subsubsection{Lymphovascular invasion in pT1 adenocarcinomas}

Definite invasion of endothelium-lined vascular spaces in the submucosa is generally regarded as a significant risk for lymph node or distant metastasis. Sometimes retraction artefact around tumour aggregates can make assessment uncertain, in which case this uncertainty should be recorded and the observation should be interpreted in a multidisciplinary conference in the light of any other adverse histological features. At the moment there are no consistent data available on the additional use of immunohistochemistry, but this might be helpful in distinguishing retraction artefacts from lymphatic (e.g. LEM D 2-40) or capillary spread (e.g. CD 34).

\subsubsection{Margin involvement in $\mathrm{pT} 1$ adenocarcinomas}

It is important to record whether the deep (basal) resection margin is involved by invasive tumour (that may be a reason for further surgery) and whether the lateral mucosal resection margin is involved by carcinoma or the pre-existing mucosal neoplasia (in which case a further local excision may be attempted) (VI-B). Rec 7.6

There has been considerable discussion and controversy in the literature over what degree of clearance might be regarded as acceptable in tumours that extend close to the deep submucosal margin [8]. It is important that clearance be measured and recorded in the report. All would agree that a clearance of $0 \mathrm{~mm}$, and most would agree that a clearance of $<1 \mathrm{~mm}$ is an indication for further therapy, others would use $<2 \mathrm{~mm}$. We currently recommend that clearance of $1 \mathrm{~mm}$ or less indicates margin involvement (VI-B). However, this may be handled by removal of any residual polyp endoscopically.

\section{5.3.5 Tumour cell budding in pT1 adenocarcinomas}

Tumour cell budding, i.e., the presence of small islands or single infiltrating tumour cells at the front of tumour invasion, has been described in the Japanese literature as an unfavourable prognos- tic factor if present in a marked degree $[32,50,69]$. Budding has been assessed either as slight, moderate or marked; or as present/absent $[13,77]$. However, its reproducibility has been criticised, the diagnostic criteria vary [41] and the ability to predict metastasis compared to the previously discussed factors is unproven. Further research is needed in this area to identify the optimum method and its reproducibility before tumour cell budding can be recommended for routine use as an indicator of metastasis. Please see annex for details [73].

\subsubsection{Site}

The site of origin of each specimen should be individually identified by the clinician and provided to the pathologist on the request form (VI-B). ${ }^{\text {Rec }} 7.15$ This should preferably include both the segment of the bowel and the distance in $\mathrm{cm}$ from the anus. The pathologist should record this information on the proforma. This is important as the risk of lymph node metastases from a T1 adenocarcinoma has been reported to vary depending on the site of the lesion [39].

\subsection{Specimen handling}

Specimen handling is an important issue, as poor handling and dissection procedures can impair diagnostic accuracy. Specimen handling starts with the endoscopic removal of the specimen and ends with the histopathological diagnosis and report. The need for a close relationship between endoscopists and histopathologists is stressed.

\subsubsection{Submission of specimens}

It is recommended to place specimens in separate containers, one for each lesion, to avoid confusion about exact location; if lesions are small, individual cassettes or multicassettes can be used. Biopsies from the same lesion can be placed in the same container. For endoscopic resections it is helpful to pin out specimens by inserting pins through the periphery of the specimen onto cork or thick paper. Too much tension on the specimen could result in artificially thinned lesions. Needles should not be placed directly through a lesion but at the margin. Besides patient data, an exact description on location should be provided (e.g. cms from anocutanous line), as well as size and morphology (stalked polyp, non-polypoid - Paris classification, etc.). Additional information about central depression or focal erosion or ulceration or 
coexistent chronic inflammatory bowel disease can be useful. Endoscopic pictures can also be submitted with the specimen(s).

\subsubsection{Fixation}

Fixation should be by buffered $10 \%$ formalin; this equals a roughly $4 \%$ paraformaldehyde concentration, as formalin is $30-40 \%$ paraformaldehyde. Specimen(s) can shrink due to formalin fixation, therefore measurements taken after fixation can differ from those prior to fixation. Fixation in alcohol is not recommended and if any other fixatives are used a comparative study of size of adenomas after fixation should be performed prior to use to avoid excessive shrinkage of adenomas to avoid under treatment.

\subsubsection{Dissection}

The pathologist should verify the complete removal of neoplastic lesions (clear margins) and the absence of submucosal invasion in biopsy specimens. Currently we recommend that clearance of 1 $\mathrm{mm}$ or less indicates margin involvement (VI-B). Cases of incomplete removal or uncertainty about submucosal invasion should be highlighted in the pathology report (VI-B). ${ }^{\text {Rec }}{ }^{7.6}$ Lesion size should be given in millimetres. Size should be carefully measured identifying the maximum diameter of the adenomatous component as well as the distance to the margin of excision(s) to within a $m m(V-B) .^{\text {Rec } 7.8}$

Given the small dimensions of the submucosal layer, infiltration into the submucosal level should be measured in microns from the bottom line of the muscularis mucosae $(\mathbf{V I}-\mathbf{B}) .^{\text {Rec } 7.8}$

\subsubsection{Polypoid lesions}

Polyps must be sliced and totally embedded. Special attention should be paid to the resection margin, which should be identified and described (dot-like, broad, stalked, etc.) and either dissected tangentially into an extra cassette or sliced in a way that allows complete assessment.

\subsubsection{Mucosal excisions}

Mucosal excisions need to be pinned out on a cork board or on another suitable type of material, fixed, described and dissected allowing the identification of involvement of the deep and lateral surgical margins. Particular attention should be paid to any areas of ulceration or induration for signs of invasion. Inking margins is recommended.

\subsubsection{Piecemeal removal}

If it is possible to reconstruct a lesion removed piecemeal it may be helpful, but this is not commonly the case. It is good practice to embed the entire lesion to allow exclusion of invasive malignancy. Occasionally, whole embedding will not be possible.

\subsubsection{Sectioning and levels}

Three or more levels should be cut through each block and stained with haematoxylin and eosin.

\subsubsection{Surgically-removed lesions}

7.6.5.1 Classification The staging of colorectal cancer can be undertaken by a number of different systems. The two used in Europe are TNM and the older Dukes classification. Originally the Dukes classification system placed patients into one of three categories (stages A, B, C) (see $\bullet$ Tab. 7.2). This system was subsequently modified by dividing stage $\mathrm{C}$ into stage $\mathrm{C} 1$ and $\mathrm{C} 2$ and the addition of a fourth stage (D). More recently, the Union Inter- nationale Contra le Cancer (UICC) and the American Joint Committee on Cancer (AJCC) has introduced the TNM staging system, that places patients into one of four stages (Stage I-IV). TNM is superior to Dukes because of the greater information it yields, but there are currently major issues due to the periodic reclassification of this system that can lead to stage migration.

TNM has a number of versions, so the version used should be noted in brackets (e.g. v5, v6, v7). $\odot$ Tab. 7.3 permits comparison of the most recent versions, 5, 6 and 7 [58-60]. However, there are differences between the versions, particularly regarding the notes on $\mathrm{T}$ and $\mathrm{N}$ classification. There is also variation between countries as to the TNM classification used. For example, TNM 5 is recommended in the United Kingdom, Holland, Belgium and Denmark and is growing in popularity in other countries.

In the USA version 7 is used. TNM 7 appears to be more subjective than TNM 5 due to the notes on $\mathrm{N}$ classification and the category N1c, promoting stage migration from II to III $[24,42,45]$. National results should be reported with the version of TNM used in a given country (VI-B). ${ }^{\text {Rec }} 7.3$

\subsubsection{Practical issues}

High-quality reporting of colorectal cancer is very important both to the clinicians treating the patients and to the cancer registry. The introduction of a 'minimum' data proforma template allows more complete reporting compared with interpretation of free text reports by medical staff $[3,5,11,16,40,44,46,79]$. All biopsies and lesions identified in the screening programme and the subsequent resection specimens should be reported on a paper or electronic proforma (II-B) in a timely manner and in a minimum of $90 \%$ of all cases. The proforma should be sent to the referring physician, the relevant cancer registry and the screening programme (VI-B). Rec 7.11

Dissection should be according to national guidelines such as those for the United Kingdom; Royal College of Pathologists [82-84] and the NHS Bowel Cancer Screening publication [38], the Scottish clinical guidelines [56], the Dutch guidelines [71, 72], the German guidelines [53], or the Italian guidelines [47]. For examples of these guidelines see the list of websites in Appendix 4 of the full Guidelines document [55]. If national guidelines do not exist they should be created or adopted from elsewhere (VI-B). An additional free text written report is optional, but needs to include all of the data required in the proforma (VIB). $\operatorname{Rec} 7.12$

Pathologists need access to a high-quality, binocular microscope with at least the following objectives: $5 \mathrm{x}, 10 \mathrm{x}, 20 \mathrm{x}$ and $40 \mathrm{x}$ and that fulfils national guidelines such as those of the Sector Committee for Pathology and Neuropathology of the German Accreditation Body [12]. 
Table 7.3 TNM classification of tumours of the colon and rectum.

\begin{tabular}{|c|c|c|c|c|c|c|}
\hline T-Primary Tumour & \multicolumn{3}{|c|}{ Clinical Classification } & $\begin{array}{l}5^{\text {th }} \text { Edition } \\
\text { (1997) }\end{array}$ & $\begin{array}{l}6^{\text {th }} \text { Edition } \\
(2002)\end{array}$ & $\begin{array}{l}7^{\text {th }} \text { Edition } \\
\text { (2009) }\end{array}$ \\
\hline TX & \multicolumn{3}{|c|}{ Primary tumour cannot be assessed } & + & + & + \\
\hline T0 & \multicolumn{3}{|c|}{ No evidence of primary tumour } & + & + & + \\
\hline Tis $^{1}$ & \multicolumn{3}{|c|}{ Carcinoma in situ: intraepithelial or invasion of lamina propria } & + & + & + \\
\hline T1 & \multicolumn{3}{|c|}{ Tumour invades submucosa } & + & + & + \\
\hline T2 & \multicolumn{3}{|c|}{ Tumour invades muscularis propria } & + & + & + \\
\hline T3 & \multicolumn{3}{|c|}{$\begin{array}{l}\text { Tumour invades through muscularis propria into subserosa or into } \\
\text { non-peritonealised pericolic or perirectal tissues }\end{array}$} & + & + & + \\
\hline$T 4^{2,3}$ & \multicolumn{3}{|c|}{$\begin{array}{l}\text { Tumour directly invades into other organs or structures and/or } \\
\text { perforates visceral peritoneum }\end{array}$} & + & + & + \\
\hline T4a & \multicolumn{3}{|c|}{ Perforates visceral peritoneum } & - & - & + \\
\hline T4b & \multicolumn{3}{|c|}{ Directly invades other organ or structures } & - & - & + \\
\hline \multicolumn{7}{|l|}{$\begin{array}{l}\text { N-Regional Lymph } \\
\text { Nodes }\end{array}$} \\
\hline NX & \multicolumn{3}{|c|}{ Regional lymph nodes cannot be assessed } & + & + & + \\
\hline No & \multicolumn{3}{|c|}{ No regional lymph node metastasis } & + & + & + \\
\hline N1 & \multicolumn{3}{|c|}{ Metastasis in 1 to 3 regional lymph nodes } & + & + & + \\
\hline N1a & \multicolumn{3}{|l|}{1 node } & - & - & + \\
\hline N1b & \multicolumn{3}{|l|}{$2-3$ nodes } & - & - & + \\
\hline N1c & \multicolumn{3}{|c|}{ Satellites ${ }^{4}$ in subserosa, without regional nodes } & - & - & + \\
\hline N2 & \multicolumn{3}{|c|}{ Metastasis in 4 or more regional lymph nodes } & + & + & + \\
\hline N2a & \multicolumn{3}{|l|}{$4-6$ nodes } & - & - & + \\
\hline N2b & \multicolumn{3}{|c|}{7 or more nodes } & - & - & + \\
\hline M-Distant Metasta & & & & & & \\
\hline MX & Distant me & not be asse & & + & + & - \\
\hline M0 & No distant & & & + & + & + \\
\hline M1 & Distant me & & & + & + & + \\
\hline M1a & $\begin{array}{l}\text { Metastasis } \\
\text { lymph nod }\end{array}$ & one organ & vary, non-regional & - & - & + \\
\hline M1b & Metastasis & n one organ & oneum & - & - & + \\
\hline & Stage Grou & & & & & \\
\hline Stage & T-Tumour & N-Node & M-Metastasis & $\begin{array}{l}5^{\text {th }} \text { Edition } \\
\text { (1997) }\end{array}$ & $\begin{array}{l}6^{\text {th }} \text { Edition } \\
(2002)\end{array}$ & $\begin{array}{l}7^{\text {th }} \text { Edition } \\
\text { (2009) }\end{array}$ \\
\hline Stage 0 & Tis & No & M0 & + & + & + \\
\hline Stage I & $\mathrm{T} 1, \mathrm{~T} 2$ & No & M0 & + & + & + \\
\hline Stage II & $\mathrm{T} 3, \mathrm{~T} 4$ & No & M0 & - & - & + \\
\hline Stage IIA & T3 & No & M0 & + & + & + \\
\hline Stage IIB & $\mathrm{T} 4$ & No & M0 & + & + & - \\
\hline Stage IIB & T4a & No & M0 & - & - & + \\
\hline Stage IIC & T4b & NO & M0 & - & - & + \\
\hline Stage III & Any $T$ & $\mathrm{~N} 1, \mathrm{~N} 2$ & M0 & - & - & + \\
\hline Stage IIIA & $\mathrm{T} 1, \mathrm{~T} 2$ & N1 & M0 & + & + & + \\
\hline & Stage Grou & & & & & \\
\hline Stage & T-Tumour & N-Node & M-Metastasis & $\begin{array}{l}5^{\text {th }} \text { Edition } \\
(1997)\end{array}$ & $\begin{array}{l}6^{\text {th }} \text { Edition } \\
(2002)\end{array}$ & $\begin{array}{l}7^{\text {th }} \text { Edition } \\
\text { (2009) }\end{array}$ \\
\hline Stage IIIA & $\mathrm{T} 1, \mathrm{~T} 2$ & N1c & M0 & - & - & + \\
\hline Stage IIIA & $\mathrm{T} 1$ & $\mathrm{~N} 2 \mathrm{a}$ & M0 & - & - & + \\
\hline Stage IIIB & $\mathrm{T} 3, \mathrm{~T} 4$ & N1 & M0 & + & + & - \\
\hline Stage IIIB & T3,T4a & $\mathrm{N} 1 / \mathrm{N} 1 \mathrm{C}$ & M0 & - & - & + \\
\hline Stage IIIB & $\mathrm{T} 2, \mathrm{~T} 3$ & $\mathrm{~N} 2 \mathrm{a}$ & M0 & - & - & + \\
\hline Stage IIIB & $\mathrm{T} 1, \mathrm{~T} 2$ & $\mathrm{~N} 2 \mathrm{~b}$ & M0 & - & - & + \\
\hline Stage IIIC & Any $T$ & N2 & M0 & + & + & - \\
\hline Stage IIIC & T4a & $\mathrm{N} 2 \mathrm{a}$ & M0 & - & - & + \\
\hline Stage IIIC & T3,T4a & $\mathrm{N} 2 \mathrm{~b}$ & M0 & - & - & + \\
\hline Stage IIIC & $\mathrm{T} 4 \mathrm{~b}$ & $\mathrm{~N} 1, \mathrm{~N} 2$ & M0 & - & - & + \\
\hline Stage IV & Any $T$ & Any N & M1 & + & + & - \\
\hline Stage IVA & Any $T$ & Any N & M1a & - & - & + \\
\hline Stage IVB & Any $T$ & Any $\mathrm{N}$ & M1b & - & - & + \\
\hline
\end{tabular}


Table 7.3 (Continuation)

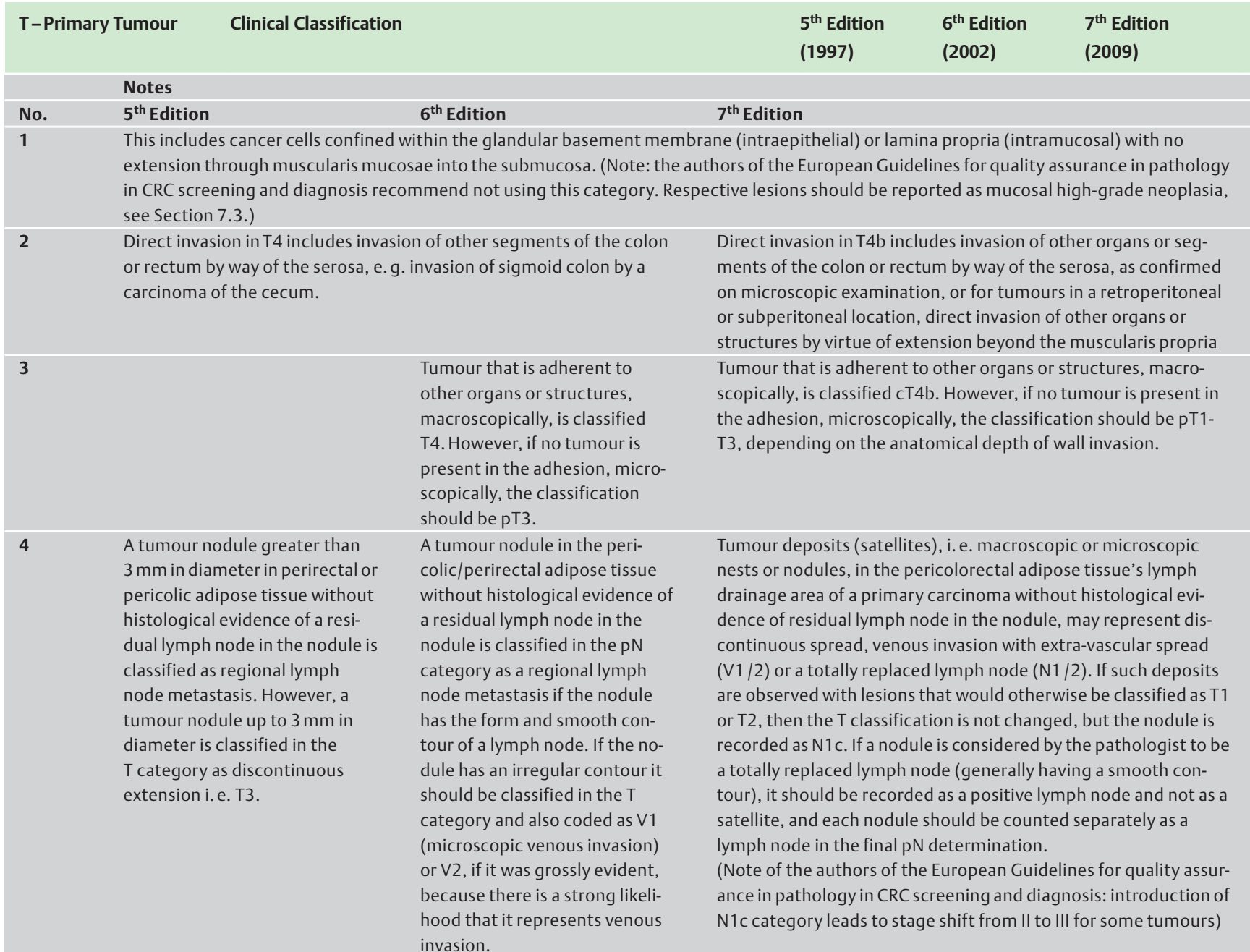

A computer is required for identifying previous material from a given patient and for filling in proformas electronically and online if secure online services are available. Adequate time must be available for dissection, reporting, and attendance at meetings of the screening team and the colorectal cancer multidisciplinary team (VI-B). ${ }^{\text {Rec }} 7.17$ Time and funding are required for pathologists to attend national meetings on the screening programme and continued training in histopathology of colorectal neoplasia. Pathologists should attend one refresher training course every year on the pathology of colorectal neoplasia to maintain quality. (VI-B). Rec 7.22

\subsection{Standards and quality indicators}

There should be good communication between members of the screening team with agreed terminology, regular meetings and clinical discussions (VI-B). Rec 7.16

An external quality assurance programme should be put in place, specifying a minimum of two slide circulations per year of an adequate number of slides (VI-B). ${ }^{\text {Rec }} 7.17$ This may be via clusters or cells of pathologists using glass slides, or can be electronic using images or virtual slides [48] distributed via DVD or the web (see http://www.virtualpathology.leeds.ac.uk). There should be external oversight of such programmes. In the absence of evidence-based guidelines we recommend that pathologists report- ing in a colonoscopy programme should not report high-grade neoplasia in more than $5 \%$ of lesions and those in an FOBT programme in not more than $10 \%$ of lesions (VI-B). ${ }^{\text {Rec }} 7.21$

The pathologists reporting in the programme must meet their national criteria for safety in reporting colorectal cancer (VIB). ${ }^{\text {Rec }} 7.19$ Departments and pathologists taking part in screening programmes should audit their own reporting practices for key features, including the number of lymph nodes retrieved, the frequency of circumferential resection margin involvement (CRM) and the frequency of high-risk features such as extramural vascular invasion and peritoneal invasion reported (VI-B). ${ }^{\operatorname{Rec}}$ 7.18, 7.20 In the UK, national standards suggest that the number of nodes retrieved should be above a median of 12 , CRM positivity in rectal cancer should be below $15 \%$, extramural vascular invasion reported in more than $25 \%$, and peritoneal invasion in more than $20 \%$. The laboratory must be able to demonstrate participation in a laboratory technical external quality assurance programme, such as Clinical Pathology Accreditation UK (http:// www.cpa-uk.co.uk/), the ISO/IEC accreditation developed by the Sector Committee for Pathology and Neuropathology of the German Accreditation Body (http://www.dakks.de/, see also [49]), or other national standards (VI-C). ${ }^{\text {Rec }} \mathbf{7 . 2 3}$ 


\subsection{Data collection and monitoring}

Lesions reported in the screening programme should be reported by proforma (II-B) or structured reporting, and the data returned to the screening programme or national tumour registries. This will include all lesions identified and the subsequent resection specimen. This should occur in a minimum of $90 \%$ of all cases (VI-B). ${ }^{\text {Rec } 7.11}$

Studies have shown discrepancy between the histopathology of biopsies and total removal by polypectomy, EMR and surgical specimens. Colorectal cancer was detected in surgical specimens in over $20 \%$ of biopsies diagnosed with high-grade neoplasia [19]. Sub-mucosal invasion was detected in surgical specimens in over $25 \%$ of cases with mucosal neoplasia [67]. Therefore the correlation between histological diagnosis of biopsies and resections should be reported. Any lack of correlation should be discussed by the multi-disciplinary team and the results of this discussion should be documented (III-B). ${ }^{\text {Rec } 7.13}$

Pathologists must ensure that their proformas are received by the screening programme coordinators or a cancer registry for the purposes of clinical management, audit and quality assurance (VI-B). Rec 7.14

Results from the key indicators of quality should be returned for analysis to the funding body: either the Health Authority or the national screening programme's offices (VI-B). Rec 7.14

Statistics should include the frequency of colorectal cancer and the distribution of TNM stages and version used; as well as the distribution of the type of lesion, size, location, frequency of grades of dysplasia and villousness (villous, tubulo-villous or tubular) and presence of non-neoplastic lesions. (VI-B). .Rec $7.15^{-15}$

\subsection{Images}

A selection of images and digital slides showing the histopathology of lesions commonly detected in screening programmes, as well as some images illustrating pitfalls in histopathologic interpretation is provided in the internet at http://www.virtualpathology.leeds.ac.uk (go to: "European Guidelines for quality assurance in pathology in colorectal cancer screening and diagnosis-Imaging library"). The site has been created to establish an initial, quality-assured repository for images illustrating the present chapter. The images are provided for reference and have been reviewed by pathologists from at least three European countries. We encourage colleagues to submit further images which they feel could be instructive or otherwise useful in illustrating or further developing the European Guidelines.

We also aim to extend the scope of this site in the future to promote pan-European and international collaboration in training and in expanding the evidence base for further advances in colorectal cancer screening and diagnosis.

\section{Conclusions \\ $\nabla$}

In a multidisciplinary process, wide consensus has been achieved on a comprehensive package of evidence-based recommendations for quality assurance in pathology in colorectal cancer screening and diagnosis. Following these recommendations has the potential to enhance the control of colorectal cancer in Europe and elsewhere through improvement in the quality and effectiveness of the screening process that extends from systematic invitation to management of screen-detected cases. The availability of a uniform classification for reporting lesions detected in screening programmes in Europe also has the potential to im- prove international collaboration and exchange of experience in improving the quality and effectiveness of colorectal cancer care.

\section{Disclaimer}

$\nabla$

The views expressed in this document are those of the authors. Neither the European Commission nor any person acting on its behalf can be held responsible for any use that may be made of the information in this document.

\section{Competing interests: No competing interests reported.}

\author{
Institutions \\ 1 Pathology and Tumour Biology, Leeds Institute of Molecular Medicine, \\ University of Leeds, Leeds, United Kingdom \\ 2 Pathology Department, Institute for Cancer Research and Treatment, Turin, \\ Italy \\ ${ }^{3}$ Screening Group, Early Detection and Prevention Section, International \\ Agency for Research on Cancer, Lyon, France \\ ${ }^{4}$ Quality Assurance Group, Early Detection and Prevention Section, \\ International Agency for Research on Cancer, Lyon, France \\ ${ }^{5}$ Institute of Pathology, Klinikum Bayreuth, Bayreuth, Germany
}

\section{Acknowledgements \\ $\nabla$}

A preliminary version of this chapter with the same recommendations, but with a slightly different format and text has been published elsewhere [43].

The comments and suggestions received from the following reviewers are gratefully acknowledged:

Bob Riddell, Canada, Hiroshi Saito, Japan and Hidenobu Watanabe, Japan.

The comments and suggestions received from consultation of the European Cancer Network are gratefully acknowledged.

Some of the material contained in these Guidelines is reproduced with permission of the UK bowel cancer screening programme pathology screening committee (Carey F, Mapstone N, Quirke P, Shepherd N, Warren B, Williams G) and the Royal College of Pathologists minimum dataset for colorectal cancer reporting (Williams G, Quirke P, Shepherd N).

Phil Quirke is supported by Yorkshire Cancer Research and the Department of Health/Cancer Research UK Experimental Cancer Medicine Centre Initiative.

The assistance of Dr Tilman Schulz, Bayreuth, Germany, in the creation of illustrations is gratefully acknowledged.

The production of the Guidelines was supported by the European Union through the EU Public Health Programme, (grant agreement no. 2005317: Development of European Guidelines for Quality Assurance of Colorectal Cancer Screening). Partner institutions: Oxford University Cancer Screening Research Unit, Cancer Epidemiology Unit, University of Oxford, Oxford, United Kingdom; Unit of Cancer Epidemiology, Centre for Cancer Epidemiology and Prevention (CPO) and S. Giovanni University Hospital, Turin, Italy; Public Association for Healthy People, Budapest, Hungary; European Cancer Patient Coalition (ECPC), Utrecht, Netherlands; Quality Assurance Group, Section of Early Detection and Prevention, International Agency for Research on Cancer, Lyon, France.

Financial support was also received through the Public Affairs Committee of the United European Gastroenterology Federation, and from a cooperative agreement between the American Cancer Society and the Division of Cancer Prevention and Control at the Centers for Disease Control and Prevention. 


\section{References}

1 Atkin $W$, Valori R, Kuipers EJ et al. European guidelines for quality assurance in colorectal cancer screening and diagnosis. First edition. Colonoscopic surveillance following adenoma removal. Endoscopy 2012; 44: SE151-SE163

2 Austoker J, Giordano L, Hewitson P et al. European guidelines for quality assurance in colorectal cancer screening and diagnosis. First edition. Communication. Endoscopy 2012; 44: SE164-SE185

3 Beattie GC, McAdam TK, Elliott $S$ et al. Improvement in quality of colorectal cancer pathology reporting with a standardized proforma-a comparative study. Colorectal Dis 2003; 5: 558 - 562

4 Blumberg D, Paty PB, Guillem JG et al. All patients with small intramural rectal cancers are at risk for lymph node metastasis. Dis Colon Rectum 1999; 42: $881-885$

5 Branston LK, Greening S, Newcombe RG et al. The implementation of guidelines and computerised forms improves the completeness of cancer pathology reporting. The CROPS project: a randomised controlled trial in pathology. Eur J Cancer 2002; 38: 764-772

6 Burt R, Jass J. Hyperplastic Polyposis. World Health Organisation classification of tumours: Pathology and genetics of tumours of the digestive system. Lyon: IARC Press; 2000: 135-136

7 Cooper HS, Deppisch LM, Gourley WK et al. Endoscopically removed malignant colorectal polyps: clinicopathologic correlations. Gastroenterology 1995; 108: 1657-1665

8 Cooper HS, Deppisch LM, Kahn EI et al. Pathology of the malignant colorectal polyp. Hum Pathol 1998; 29: 15-26

9 Council of the European Union. Council Recommendation of 2 December 2003 on cancer screening (2003/878/EC). Off J Eur Union; 2003: $34-38$

10 Coverlizza S, Risio M, Ferrari A et al. Colorectal adenomas containing invasive carcinoma. Pathologic assessment of lymph node metastatic potential.. Cancer 1989; 64: 1937-1947

11 Cross SS, Feeley KM, Angel CA. The effect of four interventions on the informational content of histopathology reports of resected colorectal carcinomas. J Clin Pathol 1998; 51: 481-482

12 DAP-TM-30. Leitfaden zur Interpretation der Anforderungen der DIN EN ISO/IEC 17020 : 2004 und technische Kriterien fuer deren Anwendung zur Akkreditierung in der Pathologie/Neuropathologie. 2007: http://www.dap.de/95doc/DAP-TM-30.pdf Accessed 11/2/2012

13 Deinlein $P$, Reulbach $U$, Stolte $M$ et al. Risk factors for lymphatic metastasis from pT1 colorectal adenocarcinoma. Pathologe 2003; 24: 387 393

14 Dixon MF. Gastrointestinal epithelial neoplasia: Vienna revisited. Gut 2002; $51: 130-131$

15 EC Working Group on Breast Screening Pathology. Quality assurance guidelines for pathology. Open biopsy and resection specimens. In: Perry N, Broeders M, de Wolf C et al. (eds.) European guidelines for quality assurance in breast cancer screening and diagnosis. 4th: edition Luxembourg: Office for Official Publications of the European Communities; 2006

16 Eon Y, Le Douy JY, Lamer B et al. Quality and completeness of histopathology reports of rectal cancer resections. Results of an audit in Brittany.. Gastroenterol Clin Biol 2006; 30: 235 - 240

17 Fenger $C$, Bak $M$, Kronborg $O$ et al. Observer reproducibility in grading dysplasia in colorectal adenomas: comparison between two different grading systems. J Clin Pathol 1990; 43: 320-324

18 Ferlay J, Shin HR, Bray F et al. GLOBOCAN 2008 v1.2, Cancer Incidence and Mortality Worldwide: IARC CancerBase No. 10. [Internet] Lyon, France: International Agency for Research on Cancer; 2010: Available from: http://globocan.iarc.fr Accessed on 05/04/2012

19 Gondal G, Grotmol T, Hofstad B et al. Biopsy of colorectal polyps is not adequate for grading of neoplasia. Endoscopy 2005; 37: 1193-1197

20 Haggitt RC, Glotzbach RE, Soffer EE et al. Prognostic factors in colorectal carcinomas arising in adenomas: implications for lesions removed by endoscopic polypectomy. Gastroenterology 1985; 89: 328-336

21 Halloran S, Launoy G, Zappa M. European guidelines for quality assurance in colorectal cancer screening and diagnosis. First edition. Faecal Occult Blood Testing. Endoscopy 2012; 44: SE65-SE87

22 Hassan C, Zullo A, Risio M et al. Histologic risk factors and clinical outcome in colorectal malignant polyp: a pooled-data analysis. Dis Colon Rectum 2005; 48: 1588-1596

23 Jass JR, Baker K, Zlobec I et al. Advanced colorectal polyps with the molecular and morphological features of serrated polyps and adenomas: concept of a "fusion" pathway to colorectal cancer. Histopathology 2006; 49: $121-131$
24 Jass JR, O'Brien J, Riddell $R H$ et al. Recommendations for the reporting of surgically resected specimens of colorectal carcinoma: Association of Directors of Anatomic and Surgical Pathology. Am J Clin Pathol 2008; 129: $13-23$

25 Jass JR, Williams CB, Bussey HJ et al. Juvenile polyposis-a precancerous condition. Histopathology 1988; 13: 619-630

26 Kikuchi R, Takano M, Takagi K et al. Management of early invasive colorectal cancer. Risk of recurrence and clinical guidelines. Dis Colon Rectum 1995; 38: 1286-1295

27 Kudo S. Endoscopic mucosal resection of flat and depressed types of early colorectal cancer. Endoscopy 1993; 25: 455-461

28 Kudo S, Lambert R, Allen JI et al. Nonpolypoid neoplastic lesions of the colorectal mucosa. Gastrointest Endosc 2008; 68: 3-47

29 Landsorp-Vogelaar I, von Karsa L. European guidelines for quality assurance in colorectal cancer screening and diagnosis: First edition. Introduction. Endoscopy 2012; 44: SE15-SE30

30 Longacre TA, Fenoglio-Preiser CM. Mixed hyperplastic adenomatous polyps/serrated adenomas. A distinct form of colorectal neoplasia.. Am J Surg Pathol 1990; 14: 524-537

31 Malila N, Senore C, Armaroli P. European guidelines for quality assurance in colorectal cancer screening and diagnosis. First edition. Organisation. Endoscopy 2012; 44: SE31 - SE48

32 Masaki T, Matsuoka H, Sugiyama M et al. Actual number of tumor budding as a new tool for the individualization of treatment of T1 colorectal carcinomas. J Gastroenterol Hepatol 2006; 21: 1115-1121

33 Minozzi S, Armaroli P, Banzi R et al. European guidelines for quality assurance in colorectal cancer screening and diagnosis - First edition. Appendix 1: Systematic evidence review. 2010: http://bookshop.europa.eu/en/european-guidelines-for-quality-assurance-in-colorectalcancer-screening-and-diagnosis-pbND3210390/ Accessed 11/2/2012

34 Minozzi S, Armaroli P, Segnan N. European guidelines for quality assurance in colorectal cancer screening and diagnosis. First edition. Principles of evidence assessment and methods for reaching recommendations. Endoscopy 2012; 44: SE9-SE14

35 Moss S, Ancelle-Park R, Brenner $H$. European guidelines for quality assurance in colorectal cancer screening and diagnosis. First edition. Evaluation and interpretation of screening outcomes. Endoscopy 2012

36 Muto T, Bussey HJ, Morson BC. Pseudo-carcinomatous invasion in adenomatous polyps of the colon and rectum. J Clin Pathol 1973; 26: 25 31

37 Nascimbeni R, Burgart LJ, Nivatvongs $S$ et al. Risk of lymph node metastasis in T1 carcinoma of the colon and rectum. Dis Colon Rectum 2002; 45: $200-206$

38 NHS Bowel Cancer Screening Programme. Reporting lesions in the NHS Bowel Cancer Screening Programme - guidelines from the Bowel Cancer Screening Programme Pathology Group. 2007: http://www. cancerscreening.nhs.uk/bowel/publications/nhsbcsp01.pdf Accessed $11 / 2 / 2012$

39 Okuyama T, Oya M, Ishikawa $\mathrm{H}$. Budding as a risk factor for lymph node metastasis in pT1 or pT2 well-differentiated colorectal adenocarcinoma. Dis Colon Rectum 2002; 45: 628-634

40 Oppong C, Robertson N, Sherwood A et al. The use of a proforma improves colorectal cancer pathology reporting. Ann R Coll Surg Engl 2002: 84: 290

41 Prall F. Tumour budding in colorectal carcinoma. Histopathology 2007; 50: $151-162$

42 Quirke P, Cuvelier C, Ensari A et al. Evidence-based medicine: the time has come to set standards for staging. J Pathol 2010; 221: 357-360

43 Quirke P, Risio M, Lambert R et al. Quality assurance in pathology in colorectal cancer screening and diagnosis-European recommendations. Virchows Arch 2011; 458: 1 -9

44 Quirke P, Williams GT. Minimum Dataset for Colorectal Cancer Histopathology Reports. London: Royal college of Pathologists; 1998

45 Quirke $P$, Williams GT, Ectors $N$ et al. The future of the TNM staging system in colorectal cancer: time for a debate? Lancet Oncol 2007; 8: $651-657$

46 Rigby K, Brown SR, Lakin G et al. The use of a proforma improves colorectal cancer pathology reporting. Ann R Coll Surg Engl 1999; 81: $401-403$

47 Risio M, Baccarini P, Casson P et al. Histopathologic diagnosis in colorectal cancer screening: guidelines. Pathologica 2006; 98: 171-174

48 Risio M, Bussolati G, Senore C et al. Virtual microscopy for histology quality assurance of screen-detected polyps. J Clin Pathol 2010; 63: 916-920 
49 Rocken C, Manke H. Accreditation in pathology. Systematic presentation and documentation of activities in pathology. Pathologe 2010; 31: $268-278$

50 Sakuragi M, Togashi K, Konishi $F$ et al. Predictive factors for lymph node metastasis in T1 stage colorectal carcinomas. Dis Colon Rectum 2003; 46: $1626-1632$

51 Schlemper RJ, Kato Y, Stolte M. Review of histological classifications of gastrointestinal epithelial neoplasia: differences in diagnosis of early carcinomas between Japanese and Western pathologists. J Gastroenterol 2001; 36: $445-456$

52 Schlemper RJ, Riddell RH, Kato $Y$ et al. The Vienna classification of gastrointestinal epithelial neoplasia. Gut 2000; 47: 251 -255

53 Schmiegel W, Reinacher-Schick A, Arnold D et al. Update S3-guideline "colorectal cancer" 2008. Z Gastroenterol 2008; 46: 799-840

54 Schoen RE, Gerber LD, Margulies C. The pathologic measurement of polyp size is preferable to the endoscopic estimate. Gastrointest Endosc 1997; 46: $492-496$

55 Segnan N, Patnick J, von Karsa L (eds.) European guidelines for quality assurance in colorectal cancer screening and diagnosis - First edition. Luxembourg: European Commission, Publications Office of the European Union; 2010

56 SIGN. Scottish Intercollegiate Guidelines Network - Guidelines for the management of colorectal cancer. 2003: http://www.sign.ac.uk/pdf/ sign67.pdf Accessed 11/2/2012

57 Snover DC, Jass JR, Fenoglio-Preiser C et al. Serrated polyps of the large intestine: a morphologic and molecular review of an evolving concept. Am J Clin Pathol 2005; 124: 380-391

58 Sobin LH, Gospodarowicz MK, Wittekind C (eds) TNM Classification of Malignant Tumours. 7th: edition Wiley-Blackwell; 2009

59 Sobin LH, Wittekind C (eds.) TNM Classification of malignant tumours. 6th: edition New Jersey: John Wiley \& Sons; 2002

60 Sobin LH, Wittekind C (eds.) TNM classification of malignant tumours. 5th: edition New York: John Wiley \& Sons, Inc; 1997

61 Soetikno RM, Kaltenbach T, Rouse RV et al. Prevalence of nonpolypoid (flat and depressed) colorectal neoplasms in asymptomatic and symptomatic adults. JAMA 2008; 299: 1027-1035

62 Steele RJC, Pox C, Kuipers EJ et al. European guidelines for quality assurance in colorectal cancer screening and diagnosis. First edition. Management of lesions detected in colorectal cancer screening. Endoscopy 2012; 44: SE140-SE150

63 Steele RJC, Rey J-F, Lambert R. European guidelines for quality assurance in colorectal cancer screening and diagnosis. First edition. Professional requirements and training. Endoscopy 2012; 44: SE106-SE115

64 Stolte $M$. The new Vienna classification of epithelial neoplasia of the gastrointestinal tract: advantages and disadvantages. Virchows Arch 2003; 442: 99-106

65 Suzuki N, Price AB, Talbot IC et al. Flat colorectal neoplasms and the impact of the revised Vienna Classification on their reporting: a casecontrol study in UK and Japanese patients. Scand J Gastroenterol 2006; 41: 812-819

66 The Paris Classification. The Paris endoscopic classification of superficial neoplastic lesions: esophagus, stomach, and colon: November 30 to December 1, 2002. Gastrointest Endosc 2003; 58: 3-43

67 Tominaga K, Fujinuma S, Endo T et al. Efficacy of the revised Vienna Classification for diagnosing colorectal epithelial neoplasias. World J Gastroenterol 2009; 15: 2351 - 2356

68 Torlakovic EE, Gomez JD, Driman DK et al. Sessile serrated adenoma (SSA) vs. traditional serrated adenoma (TSA). Am J Surg Pathol 2008; 32: $21-29$
69 Ueno H, Mochizuki H, Hashiguchi Y et al. Risk factors for an adverse outcome in early invasive colorectal carcinoma. Gastroenterology 2004; 127: $385-394$

70 Valori R, Rey J-F, Atkin $W$ et al. European guidelines for quality assurance in colorectal cancer screening and diagnosis. First edition. Quality assurance in endoscopy in colorectal screening and diagnosis. Endoscopy 2012; 44: SE88 - SE105

71 Vereniging integrale kankercentra. Colon cancer. Nation-wide guideline, Version: 2.0. 2008: http://www.oncoline.nl/richtlijn/doc/index. php?type=save\&richtlijn_id=598 Accessed $11 / 2 / 2012$

72 Vereniging integrale kankercentra. Rectal cancer. Nation-wide guideline, Version: 2.0. 2008: http://www.oncoline.nl/richtlijn/doc/index. php?type=save\&richtlijn_id=615 Accessed 11/2/2012

73 Vieth $M$, Quirke P, Lambert $R$ et al. European guidelines for quality assurance in colorectal cancer screening and diagnosis. First edition. Annex - Annotations of colorectal lesions. Endoscopy 2012; 44: SE131-SE139

74 Volk EE, Goldblum JR, Petras RE et al. Management and outcome of patients with invasive carcinoma arising in colorectal polyps. Gastroenterology 1995; 109: 1801-1807

75 von Karsa L, Anttila A, Ronco G et al. Cancer Screening in the European Union. Report on the implementation of the Council Recommendation on Cancer Screening - First Report. Luxembourg: European Commission; 2008: http://ec.europa.eu/health/archive/ph_determinants/genetics/documents/cancer_screening.pdf Accessed 11/2/2012

76 von Karsa L, Lignini TA, PatnickJ et al. The dimensions of the CRC problem. Best Pract Res Clin Gastroenterol 2010; 24: 381 - 396

77 Wang HS, Liang WY, Lin TC et al. Curative resection of T1 colorectal carcinoma: risk of lymph node metastasis and long-term prognosis. Dis Colon Rectum 2005; 48: 1182-1192

78 Washington MK, Berlin J, Branton P et al. Protocol for the examination of specimens from patients with primary carcinoma of the colon and rectum. Arch Pathol Lab Med 2009; 133: 1539-1551

79 Wei JT, Miller EA, Woosley JT et al. Quality of colon carcinoma pathology reporting: a process of care study. Cancer 2004; 100: 1262-1267

80 WHO. Histological Typing of Intestinal Tumours. In: Jass JR, Sobin LH (eds.) World Health Organisation International Histological Classification of Tumours. 30. Berlin: Springer; 1989

81 WHO. Pathology and genetics of tumours in the digestive system. Carcinoma of the colon and rectum. In: Hamilton SR, Aaltonen LA (eds.) World Health Organization International Histological Classification of Tumours. Lyon: IARC Press; 2000: 105-119

82 Williams GT, Quirke P, Shepherd NA. Dataset for colorectal cancer. 2007; 2nd: edition http://www.rcpath.org/resources/pdf/G049-ColorectalDataset-Sep07.pdf Accessed 11/2/2012

83 Williams GT, Quirke P, Shepherd NA. Dataset for colorectal cancer - Appendix C: Proforma for colorectal cancer resections. 2007; 2nd: edition http://www.rcpath.org/resources/worddocs/G049ColorectalDatasetAppendixC-Sep07.doc Accessed 11/2/2012

84 Williams GT, Quirke P, Shepherd NA. Dataset for colorectal cancer - Appendix D: Proforma for local excision specimens. 2007; 2nd: edition http://www.rcpath.org/resources/worddocs/G049ColorectalDatasetAppendixD-Sep07.doc Accessed 11/2/2012

85 Wilson JM, Jungner YG. Principles and practice of mass screening for disease. World Health Organization; 1968: http://whqlibdoc.who.int/ php/WHO_PHP_34.pdf Accessed 11/2/2012 